\title{
Tiempo y espacio en la Duat: observaciones respecto de los Libros del Más Allá del Reino Nuevo*
}

\author{
Time and Space in the Duat. \\ Remarks about The New \\ Kingdom Books of the Netherworld
}

\author{
MARIANO BONANNO**
}

Resumen: Se reflexiona sobre las categorías tiempo y espacio en un marco acotado: la Duat y la noche, donde Ra se sumerge a partir de las primeras horas de oscuridad y hasta los primeros signos del amanecer. El objeto de este estudio son los denominados Libros del Más Allá del Reino Nuevo (Libro del Amduat, Libro de las Puertas, Libro de las Cavernas y Libro de la Tierra), composiciones funerarias que decoran las tumbas reales del Valle de los Reyes, en Luxor, Egipto.

Palabras clave: espacio; tiempo; ciclicidad; Duat; Reino Nuevo.

Abstract: The article is a reflection on time and space categories in a narrow framework: Duat and night, in which Ra arrived from the first hours of darkness and to the first signs of dawn. Our study focuses on the so-called New Kingdom Books of the Netherworld (Book of Amduat, Book of Gates, Book of Caverns, and Book of the Earth), funerary compositions that decorate mainly the royal tombs in the Valley of the Kings in Luxor, Egypt.

Key words: Space; Time; Ciclicity; Duat; New Kingdom.

Recepción: 20 de julio de 2015. / Aceptación: 1 de octubre de 2015.

* El presente artículo es una versión ampliada y corregida de un excursus del capítulo 2, titulado "Tiempo y espacio en la Duat. Especificidades, relaciones y prescindencias", de mi tesis de doctorado publicada como La Duat como espacio de una dialéctica de la regeneración. In-habitación y resignificación del espacio funerario en los Textos del Amduat, Oxford, Archaeopress, 2015.

** Universidad Nacional de Buenos Aires, mbonanno1971@gmail.com 


\section{Introducción}

Antes de introducirnos en el estudio puntual del tiempo y el espacio en la Duat, es conveniente presentar una sucinta cronología de los autores que refieren a su estudio general, o bien a su ubicación o composición particular, para introducirnos no sólo en las características generales sino también en la progresiva complejización de su estudio, consecuencia del efecto conjugado de un interés creciente en el objeto Duat con la disponibilidad y el acceso a nuevos modos de abordaje.

Para tratar de entender el mecanismo de ingreso-trasladosalida del sol de la Duat es necesario comprender antes a qué aludimos cuando hablamos de Duat, y particularmente de la Duat de los Libros del Más Allá del Reino Nuevo. ${ }^{1}$

$\mathrm{La}$ vinculación de la dinámica que estos textos imprimen a la Duat no sólo como ámbito de metamorfosis solar, sino también como vehículo diario de movimientos, respiraciones, efímeros despertares y ejecuciones, se relaciona con la idea de inmutabilidad consustancial al pensamiento religioso egipcio. El eterno renacimiento era parte vital del pensamiento cíclico de los egipcios, que operaba con una lógica de retorno a los orígenes fundacionales. La amenaza y consecuente victoria -efímera, aunque plena de incertidumbre- del caos requería de un reacomodamiento que perpetuamente lo neutralizara y derrotara, también provisoriamente; por ello, es necesario detenernos en la complejidad, en la ardua tarea de su localización y composición, dado el problema que el desconcertante contexto revela. ${ }^{2}$

Pierret, ${ }^{3}$ al hacer una analogía entre la muerte y la puesta del sol, llamaba a la zona recorrida por éste durante la noche "bajo

${ }^{1}$ Para un análisis diacrónico de la Duat en los diferentes complejos textuales funerarios (Textos de las Pirámides, Textos de los Sarcófagos, Libro de los Muertos y Libros funerarios del Reino Nuevo), véase Bonanno, La Duat como espacio de una dialéctica de la regeneración, op. cit. (especialmente el capítulo 2).

2 Silvia Wiebach-Koepke, Sonnenlauf und Kosmische Regeneration. Zur Systematik der Lebensprozesse in den Unterweltsbüchern, Wiesbaden, Harrassowitz Verlag, 2007, p. 172.

${ }^{3}$ Paul Pierret, "The Dogma of the Resurrection among the Ancient Egyptians", The Old Testament Student, vol. 4, núm. 6, 1885, p. 268. 
hemisferio", mientras que Brugsch ${ }^{4}$ Lanzone ${ }^{5}$ pensaban que el viaje del sol se realizaba por el cuerpo de su madre Nut, al considerar que la Duat era el lugar comprendido entre su cuerpo y los brazos del dios Shu. Para Chassinat, ${ }^{6}$ la Duat era doble, mitad en la parte del universo atravesada por el sol en el curso de su aparición diurna, mitad en la que el dios recorre las horas de la noche.

Para Budge, ${ }^{7}$ los egipcios parecen no haberle dado una localización fija; usualmente está bajo la tierra, pero a veces más allá de la bóveda del cielo visible (el estómago de Nut) o en las aguas que ellos imaginaban se extendían por todas partes debajo del cielo y la tierra. Respecto a su geografía, compleja y variable si tenemos en cuenta lo dicho anteriormente, y basándose en la escena final del Libro de las Puertas, Budge sostiene que fuera de la cadena de montañas (que rodeaba Egipto), pero presumiblemente cerca de ella, estaba la región de la Duat; corría paralela a esas montañas y estaba sobre el plano o la tierra de Egipto, o el cielo encima de él. ${ }^{8}$

Sin nombrar explícitamente a la Duat, Kees ${ }^{9}$ veía una contradicción respecto de la ubicación del Más Allá, Jenseits; o arriba en el cielo o en la oscuridad del inframundo, Unterwelt. Para Bonnet, ${ }^{10}$ junto a una ubicación celeste, debe remarcarse su sustancia o materia ctónica por ser donde Osiris y sus seguidores viven. Wilson, ${ }^{11}$ al estructurar el cosmos egipcio, coloca a

${ }^{4}$ Heinrich Brugsch, Religion und Mytologie der Alten Aegypter, Leipzig, J. C. Hinrichs, 1891, pp. 205-206.

${ }^{5}$ Ridolfo Lanzone, Dizionario di Mitologia Egiziana. Le domicile des Esprits, París, Papyrus du Musée de Turin publié en fac-simile, 1879 [reed. 1974], p. 1.

${ }^{6}$ Émile Chassinat, "Étude sur quelques textes funéraires de provenance thébaine", Bulletin de l'Institut français d'archéologie orientale, núm. 3, 1903, pp. 134-135.

${ }^{7}$ Wallis Budge, Osiris and the Egyptian Resurrection. Illustrated after Drawings from Egyptians Papyri and Monuments, Londres-Nueva York, Warner and Putnam, 1911 [reed. 1973], p. 165.

${ }^{8}$ Wallis Budge, The Egyptian Heaven and Hell. Vol. III, Londres, Kegan Paul, Trench, Trübner \& Co. Ltd., 1905, pp. 88-89. También nos refiere que fuera de la Duat había una cadena montañosa, similar a la que abarcaba la Tierra, y por eso podemos decir que la Duat tenía forma de valle.

${ }_{9}$ Hermann Kees, Totenglauben und Jenseits vorstellungen der Alten Agypter, Leipzig, C. Hinrischs'sche Buchhandlung, 1926, pp. 428-429.

${ }^{10}$ Hans Bonnet, Reallexikon der ägyptischen Religionsgeschichte, Berlín, De Gruyter Verlag, 1952, pp. 17-20.

11 "[...] la Duat es el área entre la tierra y el contracielo en calidad de reino de los muertos inmortales". John Wilson, "Egypt”, en Henri Frankfort, Before Philosophy. The 
la Duat por debajo del $n w n(w)^{12}$ y por encima del cielo inferior $n n t$, paredra del nwen, una de las cuatro parejas de dioses primordiales de la precreación en la Ogdóada hermopolitana. Faulkner ${ }^{13}$ considera que la Duat es la luz del amanecer, cerca de la opinión de Barta, ${ }^{14}$ para quien la Duat es la región del amanecer. Para Allen ${ }^{15}$ se trata de una región cósmica, cubierta y recorrida por agua, y ubicada entre el cielo y la tierra. Altenmüller, ${ }^{16}$ por su parte, refiere que la Duat se encuentra debajo de la tierra, exactamente opuesta al cielo superior, Oberbimmel, que posteriormente en el Reino Nuevo se une con el diostierra Aker.

Espacio íntimamente vinculado, el cielo ${ }^{17}$ en la época de los Textos de las pirámides, que progresivamente y conforme la "teología" osiriana ${ }^{18}$ ganaba ascendencia en la teoría y las prácticas funerarias - incluso en el corpus mismo de estos textos-, fue reforzando un vínculo más terreno.

Intellectual Adventure of Ancient Man. An Essay on Speculative Thought in the Ancient Near East, Middlesex, Penguin Books, 1946, p. 48.

${ }^{12}$ Véase Adolf Erman y Hermann Grapow, Wörterbuch der Ägyptischen Sprache, Leipzig-Berlín, Akademie Verlag, 1971, vol. II, p. 214; Alan Gardiner, Egyptian Grammar. Being an Introduction to the Study of Hieroglyphs, Oxford, Griffith Institute, 1957, pp. 530-531.

${ }_{13}$ Raymond Faulkner, The Ancient Egyptians Pyramid Texts, Oxford, Oxford University Press, 1969, p. 72.

${ }_{14}$ Winfried Barta, Die Bedeutung der Pyramidentexte für den vestorbenen König, Múnich, Deutscher Kunstverlag, 1981, pp. 95 y ss.

${ }^{15}$ James Allen, "The Cosmology of the Pyramids Texts", en W. K. Simpson (ed.), Religion and Philosophy in Ancient Egypt, New Haven, Yale Egyptological Seminar, 1989, pp. 22-25. "Puesto que la Duat está estrechamente ligada con Orión, una constelación meridional, puede ser localizada aún más precisamente en el borde sudoriental del cielo. La entrada a la Duat, sin embargo, está en el lado opuesto del cielo, en el nordeste" (ibid., p. 19). Similar ubicación sostiene Rolf Krauss (Astronomische Konzepte und Jenseitsvorstellungen in den Pyramidentexte, Wiesbaden, Harrassowitz Verlag, 1997, pp. 207-215), para quien la estelarización es parte importante de su análisis; debajo y encima del horizonte, en el sudeste del cielo, y Wiebach-Koepke, Sonnenlauf und Kosmische Regeneration, op. cit., p. 173.

${ }^{16}$ Hartwig Altenmüller, Jenseitsvorstellungen (Ägypten), Beitrag im Internetlexikon, 2006, p. 9.

${ }^{17}$ Es Horus quien en los Textos de las Pirámides aparece más asociado a la Duat como su regente.

18 "[El dios] despierta [el dios se levanta a causa de este $3 h$ que salió de la Duat], (precisamente) Osiris Rey que salió de Geb”, Pir 1986a-b. Con Pir se alude a la nomenclatura de Kurt Sethe (Die ältagypschen Pyramidentexte nach den Papierabdrücken und Photographien des Berliner Museums, Leipzig, J. C. Hinrichs'sche Buchhandlung, 1908), que recoge 741 declaraciones y un total de 2271 líneas. 
Más generalmente, y en lo que se refiere específicamente a los Libros del Más Allá del Reino Nuevo, la Duat es el lugar en el que los difuntos aguardaban el paso de la barca solar o donde esperaban ser ajusticiados los enemigos de Osiris y Ra. Espacio por excelencia de muertos, mwret, de los "espíritus transfigurados", $3 h w$, y de la sustancia privativa de los difuntos, $b 3 w$. Asimismo, lugar en el que multitud de dioses, asistentes solares, ejecutores, monstruos, serpientes hipóstasis de Apep, serpientes ejecutoras, etcétera, se conjugaban para, al paso de Ra, activarse y con ello poner en marcha la sinergia que la presencia solar desencadenaba.

Entiendo que la circularidad ${ }^{19}$ de la Duat es el signo de la complementariedad de la interacción solar-osiriana, y la que le confiere su configuración. Un dios celeste y un dios ctónico, ambos con competencias funerarias en áreas de gravitación respectivas, determinaron su ordenación, hecho que condice la conclusión de Hornung, para quien la Duat posee una estructura dual, en el sentido de haber una celeste y una ctónica. ${ }^{20}$

En este sentido, como bien sostiene Binder, la localización de la Duat es ambigua. El reino de los muertos no puede ser concebido solamente en simples términos de "debajo de" o "más allá", sino que está asociado con el cielo-firmamento y así también con "encima de". ${ }^{21}$ Postulamos entonces para la Duat una circularidad tal como lo plantea Budge, aunque con una estructura biconfigurada, que implica una Duat celeste y una de naturaleza ctónica según lo que Hornung sostiene. ${ }^{22}$ Los ám-

${ }^{19}$ La Duat está "bajo la tierra”, unter der Erde, pero también en la oposición complementaria según creemos, "en lo profundo", die Dat tief machen, y además en "lo alto del cielo", den Himmel hoch machen. Adolf Erman y Hermann Grapow, Wörterbuch $\operatorname{der}$ Ägyptischen Sprache, Leipzig-Berlín, Akademie Verlag, 1971, vol. v, p. 415.

${ }^{20}$ Erik Hornung, "Dat", en Wolfgang Helck, Eberhard Otto y Wolfhart Westendorf, Lexikon der Ägyptologie I, Wiesbaden, Harrassowitz, 1974, col. 994 y ss.; véase también Wolfgang Westendorf, "Das Ende der Unterwelt in der Amarnazeit oder: Die Erde als Klugel”, Göttinger Miszellen, núm. 187, 2002, p. 108.

${ }^{21}$ Susanne Binder, "The Hereafter: Ancient Egyptian Beliefs with Special Reference to the Amduat", Bulletin of the Australian Center for Egyptology, núm. 6, 1995, p. 8.

22 "Oh Señor de las Formas (Osiris), gran majestad, mira. Yo vengo, la $d w 3 t$ ha sido abierta para mí, los caminos en el cielo y sobre la tierra han sido abiertos para mí, y no hay nadie que me frustre" (Textos de los Sarcófagos, 312 IV 86c-f). De un espacio, mundo inferior, pueden inferirse caminos celestes como terrenos, y sustentar 
bitos de competencia tanto de Ra como de Osiris son los que determinan esta dualidad cuya complementariedad define la naturaleza del vínculo. Menciones de una Duat o Región Superior $-d w 3 t n h r t-{ }^{23}$ y una Duat o Región Inferior, ${ }^{24} \underline{h} r t^{25} \mathrm{O}$ expresiones tales como "el cielo es para tu b3", "la tierra es tu cuerpo", ${ }^{26}$ Cielo Inferior o Bajo Cielo $(\underline{h n}) n n t^{27}$ o Cielo Superior o "cima del cielo", ${ }^{28}$ o "lo más alto del cielo", o "grande que une las dos Duat, las dos regiones de Occidente", o "la cabeza de la misteriosa está en la Duat Superior, hrt, sus dos piernas están en la Duat inferior, $\underline{h} r t{ }^{\prime},{ }^{29}$ entendemos que justifican,

así la estructura dicotómica de la Duat. Todas las transliteraciones y traducciones corren por cuenta del autor, salvo que se indique lo contrario.

23 "[...] son ellos (cuatro dioses sobre el disco) los que hacen nueva la Duat, $d w 3 t n$ hr.t (Duat superior) con esta imagen que llevan en sus manos". Libro de las Puertas, 12,1.

${ }^{24} n^{\prime \prime}$. (iw) wi $r$ hr.t d3.t, "aquellos que me conducen a lo profundo de la Duat", Tiefe der Dat. Silvia Wiebach-Koepke, "Standorte-Bewegungstypen-Kreisläufe Semantische Betrachtungen zur Dynamik der Sonnenlaufprozesse in Amduat und Pfortenbuch", Studien zur Altägyptischen Kultur, núm. 24, 1997, p. 358.

${ }^{25}$ En el Reino Medio surge el nombre diferenciado $d w 3 . t$ hr.t, "Duat inferior"; y desde el Imperio Nuevo (tumbas reales) está la confrontación entre esta Duat con la más antigua $d w z . t$ en el cielo, que en esta oposición se llama dwz.t hr.t, "Duat superior". Westendorf, "Das Ende der Unterwelt in der Amarnazeit oder", op. cit., p. 108. Textos de los Sarcófagos, 107 II 119i. El modo de cita de los Textos de los Sarcófagos se compone, tomando como ejemplo Textos de los Sarcófagos, 107 II 119i, y con la traducción de Adrian De Buck (The Egyptian Coffin Texts, 7 vols., Chicago, The University of Chicago, 1935-1961) como base, de: 1) número de declaración: Textos de los Sarcófagos, 107; 2) tomo de la traducción de De Buck: II; 3) número de parágrafo: 119, y 4) letra del parágrafo: i.

${ }^{26}$ Libro del Amduat, 3, 3. Como Duat inferior, también en El Libro de las Cavernas, 1,5: "que permanezcan (dirigido a tres serpientes del registro) entonces en sus lugares, que creen la destrucción en sus cavernas en la Duat inferior de Osiris, para custodiar a sus enemigos". El modo de cita de los Libros del Amduat se hace aquí de la siguiente manera: 1) "Libro"; 2) hora, puerta o división; 3) registro y 4) escena (según corresponda).

${ }^{27}$ En los Textos de las Pirámides, nnt o njwet, y en el Libro del Amduat, nnt ㄱ. ㄱ. Libro del Amduat, 5, 2; Textos de los Sarcófagos, 306 IV 60o, Pir. 166c, 332c, 347a, 149b. Aquí con la grafía de njwet.

${ }^{28}$ Pir. 335a. Cielo Superior y Cielo Inferior no se condicen con Duat superior y Duat inferior por cuanto en los Textos de las Pirámides el circuito es desde el primero hacia el segundo; véase Allen, "The Cosmology of the Pyramids Texts", op. cit., p. 11; mientras que en los Textos del Amduat entendemos que el circuito se complejiza $\mathrm{y}$, en todo caso, es indistinto dada la carencia de la secuencialidad de los Textos de las Pirámides y la expansión funcional de la Duat.

${ }^{29}$ Libro de las Puertas, 11, 3; Libro de las Cavernas, 3, 3, 5; Libro de la Tierra, D, 1, 3. Christian Leitz, "Die obere und die untere Dat", Zeitschrift für ägyptische Sprache und Altertumskunde, núm. 116, 1989, p. 57. En este trabajo el autor analiza, a partir de fuentes de épocas, monumentos y tumbas diferentes, las menciones, ubicaciones, 
en forma más directa unas que otras y más allá del contexto témporo-espacial, esta duplicidad ${ }^{30}$ que en los Textos del Amduat $^{31}$ deviene una contracción del espacio.

Esta propuesta supone asimilar la dicotomía Cielo-Duat u Oberwelt-Unterwelt a un solo espacio continente, Duat, como única extensión en la que el recorrido solar se produce.

Finalmente, en la diversidad de ubicaciones planteadas no debemos desestimar la posibilidad de que la Duat sea, como sugiere Allen, ${ }^{32}$ una región meramente especulativa, ${ }^{\prime} t_{3}$, fuera del alcance de los hombres, o que deba ser pensada cosmológicamente tal como Budge $\mathrm{e}^{33}$ y también Westendorf ${ }^{34}$ sostienen.

\section{Tiempo y espacio en la Duat}

Nos ocuparemos en este apartado de la concepción del tiempo en la Duat y de "la posibilidad de distinguir absolutamente" tiempo, espacio y "lo que allí se encuentra". ${ }^{35}$ Del mismo modo, la idea que al respecto - tiempo y espacio- los egipcios

funciones e interacciones entre la Duat superior e inferior y desde aquí con otros espacios; ibid., pp. 41-57.

${ }^{30}$ La geografía misma de la Duat, descrita más claramente en los Textos de las Pirámides sobre todo como complemento a las otras zonas del Más Allá real, expone en forma ostensible la dualidad cielo-tierra con sus consecuentes derivaciones (transportes, acciones, ubicaciones, etcétera) como marcos tangibles de expresiones divinas, diferenciadas aunque complementarias. No hay registro en los Textos de las Pirámides de alusiones a una Duat superior y otra inferior; esta dicotomía surge a partir de los Textos de los Sarcófagos.

${ }^{31}$ Utilizo indistintamente Textos del Amduat y Libros del Más Allá del Reino Nuevo.

${ }^{32}$ Allen, "The Cosmology of the Pyramids Texts", op. cit., p. 20.

${ }^{33}$ Budge, Osiris and the Egyptian Resurrection, op. cit., p. 108.

${ }^{34}$ Westendorf, "Das Ende der Unterwelt in der Amarnazeit oder", op. cit., p. 109; "keine physikalische, sondern eine mytische Aussagen" es la expresión que utiliza el autor para referirse a la composición y ubicación de la Duat, Unterwelt.

${ }^{35}$ Cornelius Castoriadis, La institución imaginaria de la sociedad, Buenos Aires, Tusquets, 1983 [reed. 2007], p. 300 . Si bien partiendo de un contexto histórico-social contemporáneo, Castoriadis indaga respecto a la representación que de la historia y los esquemas de sucesión, el hombre y su sociedad fueron postulando. Es pertinente su pregunta: “¿Por qué lo (al tiempo) han pensado (los hombres) como abierto o cerrado [...], o infinito, como tiempo de progreso o tiempo de fracaso, como absolutamente homogéneo o cualitativamente diferenciado?”, dada la importancia de la representación del tiempo y el espacio en la historia de la filosofía, e incluso del pensamiento científico (ibid.). 
se representaban, y en particular, la idea que se desprende de la dialéctica que en la Duat se desencadenaba. "El ciclo diario del sol por el cielo y el Inframundo se aplica sin embargo a los Libros del Más Allá no sólo como fenómeno topográfico, sino también eo ipso como fenómeno cronográfico, cuya significación es ilustrada por la variedad de difuntos". ${ }^{36}$

Como categorías de análisis pero también como aspectos configuradores de los movimientos de la Duat, "lugar de la regeneración", ${ }^{37}$ el tiempo y el espacio conforman el eje en el que puede mensurarse su naturaleza.

Podemos entender que dinámica y estática, simultaneidad y sucesión de los acontecimientos, espacialidad y temporalidad se proyectan conjuntamente en la completa composición del Amduat. ${ }^{38}$ Ello sin perder de vista que "la concepción del tiempo era, como la del espacio, cualitativa y concreta, y no cuantitativa y abstracta", ${ }^{39}$ y que en la Duat, "los límites normales de tiempo y espacio no existen". 40 "El tiempo se regenera [...] durante el viaje nocturno del sol. Ello sucede en un (oculto) espacio, la D(w)at. Esto es también importante para el significado del espacio, y la regeneración y la formación del tiempo". ${ }^{41}$

${ }^{36}$ Winfried Barta, Die Bedeutung der Jenseitsbücher für den vestorbenen König, Múnich, Deutscher Kunstverlag, 1985, p. 185. Estas variantes están dadas, según el autor, por la diversidad de nombres para cada una de las horas y las acciones que en ellas se producían; "la hora que sujeta", "la hora que oculta", "la hora que aniquila".

${ }^{37}$ Lazlo Kákosy, “Zeit”, en Wolfgang Helck y Eberhard Otto, Lexikon der Ägyptologie VI, Weisbaden, Harrassowitz, 1986, col. 1361.

${ }^{38} \mathrm{Si}$ bien con relación al Libro del Amduat, la referencia de Ina Hegenbarth-Reichardt (Von Zeiten und Räumen. Oder: Wie unendlich ist die altägyptische Ewigkeit?, Berlín, Walter De Gruyter \& Co., 2009, p. 13) bien puede ser extensiva al resto de los Libros del Más Allá. Anteriormente, la autora refiere que en el Amduat se trata de que es descrita, como es típico para el pensamiento mítico, la temporal representación espacial; ibid., p. 11.

${ }_{39}$ Henri Frankfort, El pensamiento prefilosófico, Madrid, Fondo de Cultura Económica, 1954, p. 39. También Andreas Schweizer (The Sungod's Journey through the Netherworld. Reading the Ancient Egyptian Amduat, Ithaca-Londres, Cornell University Press, 2010, pp. 205-206) sostiene que el tiempo tiene una cualidad específica, según la actividad del dios involucrado. Si allí no hay ninguna deidad gobernando, habría una condición de no tiempo, un reino más allá de la creación bajo la soberanía de Apofis.

${ }^{40}$ Jacobus Van Dijk, "The Nocturnal Wanderings of King Neferkare", en Catherine Berger, Gisèle Clerc y Nicolas Grimal (comps.), Hommages à Jean Leclant, El Cairo, Institut français d'archéologie orientale, 1994, vol. 4, p. 390.

${ }^{41}$ Hegenbarth-Reichardt, Von Zeiten und Räumen..., op. cit., p. 13. 
La concepción de un espacio para el dios decaído y amenazado por el caos se nos presenta "técnicamente" más plausible de ser explicada como aprehendida, en tanto concibamos la Duat y el mundo funerario en general como realidad de espejo de una fisonomía compartida.

Para los egipcios no hay espacios vacíos sin símbolos de vida; por el
contrario, cada espacio está lleno. Así se constituye el entorno, lo que
en él se desarrolla. La integración en un espacio representa la expe-
riencia primaria de los hombres, lo que en apariencia viene de afuera,
con una sensación espacial a la que está asociada. Por ello, para los
egipcios es "sencillamente" natural cuando el espacio como también
el caos mundanal, surgido en primer lugar, devienen una experiencia
asimilada del mundo, con la que el tiempo puede estar conectado como
categoría ordenada. ${ }^{42}$

¿Cuál es la relación espacio-tiempo?, ¿hasta qué punto son separables en la complejidad de la Duat? y, finalmente, ¿por qué decimos que es el tiempo el que determina y articula la Duat?

Comencemos por mencionar la trascendencia de la "superación" de las horas de la noche como escenario cósmico de la regeneración solar y de la conformación del mejor escenario posible para su diaria apoteosis. La división egipcia del tiempo en 12 horas nocturnas y en 12 horas diurnas, ${ }^{43}$ probablemente deducida "de los movimientos de la Tierra y de la Luna en relación el uno con el otro y con el Sol", ${ }^{44}$ emulaba, en cierta manera, la relación de complemento que en el origen de los tiempos comenzó con la indeterminación acuosa rebosante de energía y promesa contenida del Nun (océano primordial).

La importancia de la nocturnidad, ${ }^{45}$ como preparación de la posterior eclosión diurna, hace o le confiere a este tiempo par-

${ }^{42}$ Manfred Görg, Ägyptischen Religion, Stuttgart, W. Kohlhammer GmbH, 2007, p. 14.

43 "Lo que tú llevas es la noche, lo que tú traes es el día. Eres este dios que atraviesa, $d_{3}$, las horas" (Libro del Amduat, 1,3). Secuencia, objetivación y dinámica general del paso del disco.

${ }^{44}$ Stephen Quirke, Ancient Egyptian Religion, Londres, The British Museum Press, 1992, p. 41.

45 "Oh, Osiris, a la cabeza de la Duat. Yo soy Ra, dame tu mano. Soy yo quien ha recibido un $b_{3}$, que es todo poderoso desde los tiempos de los ancestros, y quien es 
ticular y acotado, la trascendencia necesaria para erigirlo en vector transitorio de la "puesta a punto" cósmica para la perpetuación de la ciclicidad.

La Duat, como escenario del proceso cósmico y en tanto espacio objetivado, se cimienta en una articulación temporal por sobre la "espacialidad", y sus transformaciones son consecuencia natural de la inevitabilidad del tiempo.

Resulta interesante el modo en que los textos aluden al "dominio" que sobre el tiempo y el espacio Ra ejercía, ${ }^{46}$ dado que "las horas siguen sus órdenes, las pone en movimiento y ordena su curso". ${ }^{47} \mathrm{Y}$ éste no es un dato menor, por cuanto su ascendencia, o dependencia, sobre, o de ambos, refuerza el vínculo de inmanencia del dios con el tiempo, simultáneamente a su relación provisoria con el espacio. En el Libro de la Tierra, ${ }^{48}$ las 12 horas de $\mathrm{Ra}$-que simbolizan las 12 horas de oscuridad-lo conducen por la Duat y establecen una estrecha conexión entre el tiempo de gestación nocturna y el espacio, Oeste, de dicho proceso.

La conjunción temporal es en este caso tributaria de un claro dominio del dios sobre la duración, ${ }^{49}$ y la convergencia de pasado-presente-futuro en un mismo (aunque no único) momento ${ }^{50}$ supone una asimilación tangible y funcional, consecuencia, entonces, de la relación de consustancialidad del tiempo con el dios.

temido por los que están en Occidente. Actúo en la Duat, yo hago que los b3w descansen en sus cuerpos [lit. penetrar en paz en los cuerpos]. Y descanso sobre mis cuerpos, la Duat conduce mi b3 al lugar de los misterios" (Libro de las Cavernas, 1,3); punto de partida para la próxima apoteosis y reconversión solar.

46 "Yo soy el grande que planeó la Duat". Libro de las Puertas, 9,1.

${ }^{47}$ Barta, Die Bedeutung der Jenseitsbücher..., op. cit., pp. 185-186.

${ }^{48}$ Libro de la Tierra, A, 1,3.

${ }^{49}$ En el Libro del Amduat, 2,3, tres dioses portan el símbolo de año, $\mid r n p t, y$ se lo entregan a $\mathrm{Ra}$, en una clara referencia a la potestad del dios sobre el tiempo. Para la relación entre la duración, 'h 'w de la vida en el Más Acá y en el Más Allá, así como las "cantidades" de tiempo de $n h \underline{h} h \mathrm{y} \underline{d} t$, véanse Jan Assmann, Zeit und Ewigkeit im Alten Ägypten. Ein Beitrag zur Geschichte der Ereigkeit, Heidelberg, C. Winter, 1975, pp. 1118; y Erik Hornung, El Uno y los Múltiples. Concepciones egipcias de la divinidad, Madrid, Trotta, 1999, p. 156.

${ }^{50}$ Las medidas del espacio y del tiempo son relativas; una hora en la nocturnidad de la Duat corresponde a un tiempo de vida completo en la Tierra. Erik Hornung, "Zur Struktur des ägyptischen Jenseitsglaubens", Zeitschrift für ägyptische Sprache und Altertumskunde, núm. 119, 1992, p. 129. 
Por otro lado, la preeminencia del tiempo ${ }^{51}$ en lo que respecta a la sistematización funcional y procesual en la Duat ${ }^{52}$ se fundaba también en las situaciones de provisoria objetivación que devenían los microcosmos manifiestos, en el sentido de los movimientos que la presencia del disco generaba en cada uno de los habitantes de la Duat.

Expresiones tales como "la oscuridad los envuelve después que ha pasado [Ra] cerca de ellos", ${ }^{53} \mathrm{o}$ "luego ellos [nueve signos $\check{s} m s$ ] se tragan sus cabezas y sus cuchillos cuando este dios les ha pasado" ${ }^{54} \mathrm{O}$ también "ellos [nueve dioses con cetros] gimen por Ra y se lamentan por el gran dios después de que ha pasado junto a ellos", ${ }^{55}$ son ilustrativas de la ascendencia de la temporalidad y su carácter configurador, así como de la relación espera (quietud)-presencia del disco (concretización)-alejamiento (estado previo).

El mismo proceso objetivador alcanza también a las horas y es ostensible sobre todo en el Libro de las Puertas, donde el dios Aken es representado sosteniendo una cuerda en su boca, de cuyos "lazos" las horas salen. "La cuerda de Aken simboliza el tiempo; precisamente los trozos de cuerda representan la creación actual, entre lo eterno dirigido contra la fuerza de la creación y la destrucción allí pasada". ${ }^{56}$

De este modo, la dinámica del tiempo en la Duat revestía una secuencialidad en lo que se refiere a la generalidad de sus

${ }^{51}$ El simbolismo de determinadas imágenes del Libro de las Puertas, 5,3; los dioses que portan a Metuty (serpiente que representa la duración) y miden la duración de la vida para los $b_{3} w$ del Oeste (véase el dios Aken, de cuya cabeza cuelga una cuerda; Libro de las Puertas, 6,1), así como ciertas representaciones enigmáticas de la segunda capilla de Tuthanhkamon, conllevan un simbolismo que consiste en un grupo de signos que pueden ser llamados imágenes del tiempo, formalmente menos elaboradas que otras escenas que relacionan más estrechamente imagen y signo. Patricia Bochi, "Images of Time in Ancient Egyptian Art", Journal of the American Research Center in Egypt, núm. 31, 1994, p. 62.

52 " [...] la institución explícita del tiempo en una sociedad arcaica no es la de un flujo homogéneo en el cual algo crece sin cesar [...], sino, mucho más, la de un ciclo de repeticiones, escandido por la recurrencia de acontecimientos naturales llenos de significaciones imaginarias o de rituales importantes". Castoriadis, La institución imaginaria de la sociedad, op. cit., p. 332.

${ }_{53}$ Libro de las Cavernas, 6,1,1.

${ }^{54}$ Libro del Amduat, 8,2.

${ }^{55}$ Libro de las Puertas, 3,3.

${ }^{56}$ Libro de las Puertas, 6,1. Friedhelm Hoffmann, "Seilflechter in der Unterwelt", Zeitschrift für Papyrologie und Epigraphik, núm. 100, 1994, pp. 342-343. 
habitantes, ${ }^{57}$ pero también una simultaneidad en lo que concierne a Ra, consecuencia de su dominio de la temporalidad, ${ }^{58}$ cuya presencia y efectos suponían, para los habitantes de la Duat, "una vida plena de sólo una hora de la noche que se corresponde con un tiempo de vida completo en la Tierra". ${ }^{59}$

La relación manifiesta entre la linealidad osiriana y la ciclicidad $\operatorname{solar}^{60}$ es análoga al carácter secuencial del vínculo de objetivación ontológica que sustentaba la totalidad de los movimientos en la Duat. Las imágenes de la eternidad, $\underline{d} t$, son "neutralizadas" al ser tragadas en su contexto por la presencia del disco, quien, a su paso, "concretizaba" (regenerando) las realidades osirianas.

Una vez dejado atrás el espacio regenerado, las tinieblas del crepúsculo, $k k w z m 3 w^{61}$-contexto funcionalmente extensible a la Duat completa- restauraban el escenario osiriano. En este marco, "corresponde" al espacio una secuencialidad derivada de su relación de contingencia con el tiempo articulador, sustentada a su vez en la capacidad solar de objetivación espacial. "Es hacia el Oeste hacia donde Ra prosigue, para iluminar a aquellos entre los cuales el cuerpo divino, $\underline{h} 3 w n \underline{t} \underline{t}$, viaja”, es la forma compendiada como, en el Libro de la Tierra, se anticipa de qué modo los rayos del disco irán descubriendo la variedad de escenarios de la Duat. "Ra ordena a las diosas de las horas, las doce hijas devoradas por la serpiente del tiempo. Se trata de un tipo de antitiempo, que simplemente ha llevado hacia una transformación en el mundo..$^{62}$

Al tempus propio involucrado en los desplazamientos solares que hacían de Ra una figura nuclear por su metamorfosis

${ }^{57}$ En el caso de los condenados, sacrificados al término de su tiempo (Libro de las Puertas, 4,1), o de la duración de la vida [...] para los b3w del Oeste (Libro de las Puertas, 5,3), las limitaciones impuestas por su condición les evitaba dicha secuencialidad.

${ }^{58}$ En efecto, doce dioses dicen a Ra: "perpetuo, señor de los años, que no tiene disminución" (Libro de las Puertas, 5,3).

${ }^{59}$ Erik Hornung, "Die Verborgene Raum der Unterwelt in der ägyptischen Literatur", en A. Loprieno (ed.), Mensch und Raum von der Antike bis zur Gegenwart, Múnich-Leipzig, K. G. Saur, 2006, p. 26.

${ }^{60}$ A partir de la communis opinio, que vincula a $n h h$ con "el movimiento eterno por su cíclico transformarse", y a $\underline{d} t$ con la "duración eterna de la completa inmutabilidad estática”. Assmann, Zeit und Ewigkeit im Alten Ägypten, op. cit., pp. 41 y ss.

${ }^{61}$ Libro de las Cavernas, $1,1$.

${ }^{62}$ Libro de la Tierra, A, 1,1. Kákosy, "Zeit”, op. cit., col. 1363. 
Esquema 1: Las fases del viaje solar

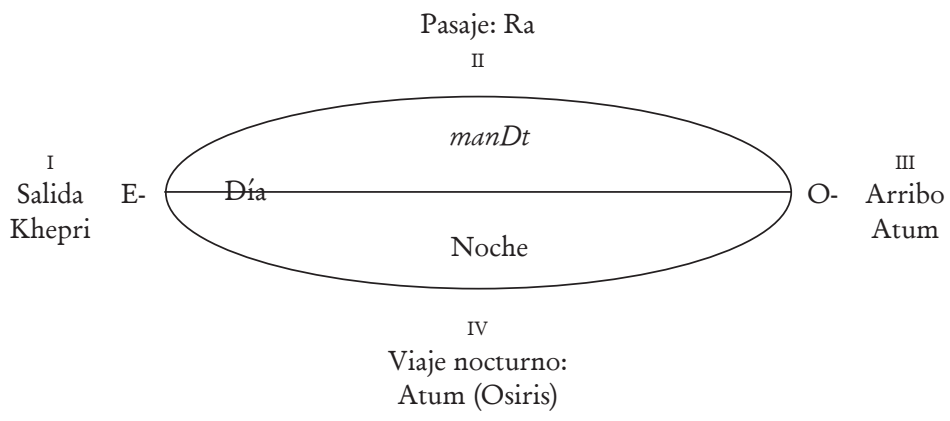

Jan Assmann, "Sonnengottes", Lexikon der Ägyptologie, Wiesbaden, Harrassowitz, 1984, vol. v, cols. 1087-1094.

gradual, integral y distintiva durante la noche, se superponían o, mejor, se le subsumían como sus derivaciones objetivadoras y objetivantes los microtempus ${ }^{63}$ propios de los habitantes o grupos de habitantes y sus espacios respectivos.

Era la noche, entonces, sostenida en el arco temporal que suponía el complejo de transferencia y conversión ontológica, disminución - procesos de reconversión, potenciación, objetivación-, reaparición, el tiempo formativo y determinante de los espacios de la Duat; era el despliegue secuencial del tiempo, tempus gestatio, el eje directriz que daba entidad al espacio circundante y continente. Finalmente, era el tiempo el que objetivaba el espacio, no por una relación de consecuencia sino en virtud de la inmanencia de una complementariedad que ocasionalmente se autonomizaba, disociaba o difuminaba, según el contexto que la temporalidad determinaba.

Así se describe este proceso en las fuentes: "Él [Ra] las llama [a las horas]. En cuanto a ellas, van detrás de él. Su luz va hacia ellas cuando salen de los cuerpos cuyos misterios están ocultos. Luego el gran dios va detrás de sus horas, mientras que los que han sido dejados atrás hacen sus transformaciones”. ${ }^{64}$

${ }^{63}$ Entre las actividades o funciones de Ra en la Duat en relación con sus habitantes, conocer sus misteriosas horas (Libro del Amduat, 6, Int.) era consecuencia tanto de su omnisciencia como de su capacidad de objetivación.

${ }^{64}$ Libro de la Tierra, D, 1,2. 
Figura 1: Entrada de los cuerpos en el Abismo. Las horas de Ra (Libro de la Tierra, D, 1,2)

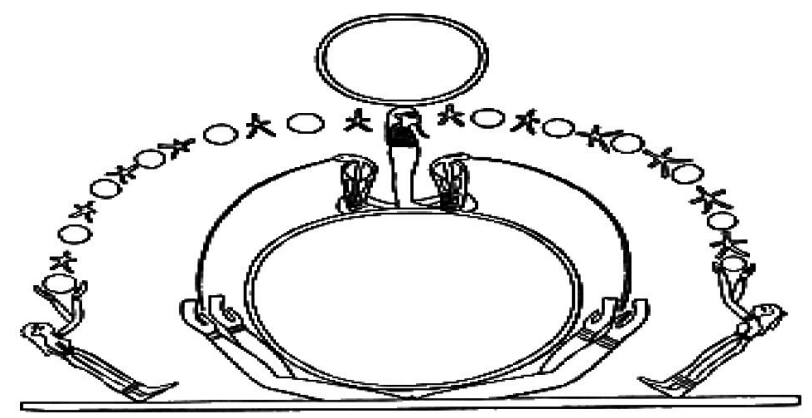

Alexandre Piankoff, The Tomb of Ramesses VI, 2 vols., Nueva York, Pantheon Books, 1954, fig. 111.

El llamado de Ra objetivaba ${ }^{65}$ y daba entidad a las horas por su condición de rector y hacedor del tiempo, dado que eran su paso y su metamorfosis nocturno-diurna los que determinaban la temporalidad. Las estrellas y los discos ${ }^{66}$ devienen así manifestaciones ostensibles de su estado y situación, hecho reforzado debido a que Amonet (la Oculta) es el nombre de la diosa que a cada lado del disco recibe a los seis que pasan en el séquito de Ra, entorno mistérico de constitución del devenir.

"Las horas van detrás de Ra", y "Ra va detrás de las horas" -paráfrasis del texto que acompaña a la representación- es la dialéctica que involucra, además de la progresiva transformación-regeneración ontológica solar, la totalidad del tiempo (de Ra y por extensión del conjunto) y su génesis cíclica. "Yo [Ra] nazco, ustedes [las horas] nacen, cuando yo vengo a la

${ }^{65}$ Como la comida, los dichos del dios sol hacen que los habitantes de la Duat "vivan"; como dadores de aire, sus palabras los hacen a ellos "respirar". Esto se corresponde perfectamente con la idea del lenguaje como una fuerza animadora; Jan Assmann, Egyptian Solar Religion in New Kingdom. Re, Amun and the Crisis of Polytheism, Nueva York, Kegan Paul, 1995, p. 22.

${ }^{66}$ Según Winfried Barta (Komparative Untersuchungen zu vier Unterweltsbüchern, Fráncfort del Meno-Berna-Nueva York-París, Peter Lang, 1994, p. 62), la multiplicación de figuras de Osiris y discos solares indican la permanente repetición de la periodicidad del ciclo del sol. 
Esquema 2: Los espacios en los diferentes Libros de Más Allá del Reino Nuevo

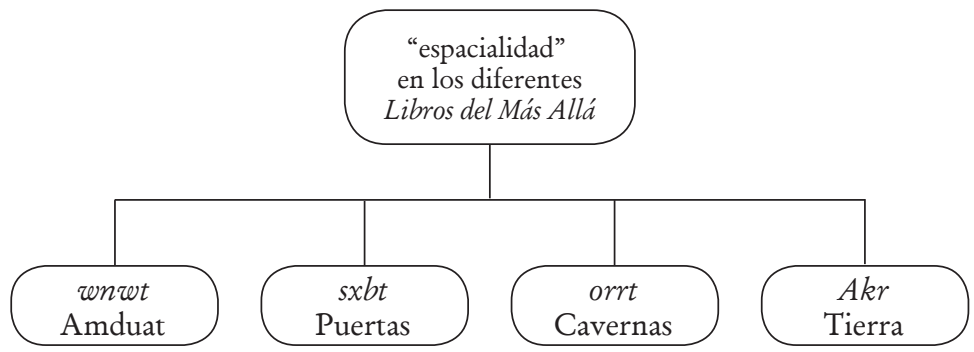

existencia ustedes vienen a la existencia. Ustedes establecen los periodos de vida y los años de aquellos entre quienes están". ${ }^{67}$

El espacio, vector formativo de la in-habitación ${ }^{68}$ nocturna, y cuya diferente descripción es "lo que determina las diferentes composiciones" (Libros del Más Allá del Reino Nuevo), es la marca diferencial que opera en este caso en dos niveles; en el más general, como contexto provisorio integral en el -y por el- que la relación se determinaba. En el particular del vínculo, por otro lado, en la "irrupción" de una entidad, Ra, en los dominios circunscritos de otra, Osiris.

En este punto se hace manifiesto el tenor y las "proporciones" de la relación entre ambos; es en el espacio creado por $\mathrm{Ra}$, del que Osiris era su rector confinado y al que aquél se remitía en su decrepitud, donde la regeneración ambivalente se desencadenaba. Ello supone una verticalidad que explica la centralidad solar y, desde aquí, sus derivaciones, en escala

${ }^{67}$ Libro de las Puertas, 11,3.

${ }^{68}$ Así entiendo el vínculo que se establece en la Duat entre Ra y Osiris durante el viaje nocturno del primero. Del latín inhabitare, derivado del verbo griego oikein - olkécu- (habitar) y éste a su vez de oikía, oıkía (casa). Prefiero in-habitación a inhabitación, dado que la separación del prefijo del término, además de mantener la independencia de sus componentes (del término), destaca el proceso que pretendemos individualizar y analizar. Es cierto, por otro lado, que el término "inhabitación" figura en el diccionario de la Real Academia Española con la acepción propia de la terminología teológica, lo que podría ser un argumento en contra de su utilización. No obstante, por tratarse de términos técnicos que provienen del ámbito de los estudios teológicos, el término no sólo es pertinente sino necesario.

${ }^{69}$ Hartwig Altenmüller, Jenseitsbücher, Jenseitsfübrer, Leiden-Colonia, E. J. Brill, 1970, p. 70. 
individual primero, Osiris, y en el conjunto luego como su correlato.

Finalmente, la idea de espacio aparece, en un nivel teológico más complejo, en el hecho de compartir, comunicar y conllevar ambos dioses una realidad ontológica de caducidad e incertidumbre e involucrarse tanto espacial como ontológicamente en secuencias -en las imágenes y sus textos respectivos- de visita, inspección y reciprocidad asimétrica. ${ }^{70}$

Este Gran Dios viaja por esta ciudad por el agua; rema en este campo en la vecindad del cadáver de Osiris. Este Gran Dios da órdenes a aquellos dioses que están en los campos. Él atraca junto a esas misteriosas mansiones que contienen las imágenes de Osiris. Este dios llama por encima de estas misteriosas mansiones. ${ }^{71}$

Espacialidad objetivada y espacialidad ontológica, compendiada en la ecuación debilidad $\rightarrow$ re-conversión (intercambio) $\rightarrow$ apoteosis, se sujetan al núcleo mismo de la in-habitación; esto es, a la dialéctica de la doble transferencia. Las consecuencias de los efectos inmediatos de Ra sobre Osiris en la Duat suponen una incidencia directa sobre la espacialidad y su constitución en la Duat, " $¡ V$ Vive Osiris! El aire es para ti, para que tu $b_{3}$ respire, mientras que tú rodeas la Duat"..$^{72}$

En lo que respecta a la vulnerabilidad de Ra, exige éste colaboración y asistencia; "Dioses, que se regocijan en mi encuentro, denme su mano, recíbanme, condúzcanme a los caminos del Occidente para que pueda dar vida a los cuerpos que están allí [...] Yo paso dentro de su morada para que puedan conducir mi $b_{3}{ }^{73}$

Esta permanente objetivación de la "secuencialidad", condicionada a las cesiones de $\mathrm{Ra}$, a los aportes, sinergia, de los habitantes de la Duat y la transmisión osiriana de la capacidad de permanencia para la renovación -inalterabilidad contenida en la asimilación del concepto de $\underline{d} t$ a Osiris y su reino-genera la paradoja de un espacio continente, intrínseco, inherente al vínculo, pero gradualmente deconstruido, descubierto y "ob-

\footnotetext{
70 Por ser Ra el motoris causa de todo proceso nocturno en la Duat.

${ }^{71}$ Libro del Amduat, 6,2.

${ }^{72}$ Libro de las Cavernas, 4,1,1.

${ }^{73}$ Libro de las Cavernas, 1,4.
} 
jetivado" en consonancia con la presencia del disco y sus derivaciones.

Los Libros del Más Allá descubren ostensiblemente la realidad de lo que el movimiento desvelaba; vale decir que verdaderas sucesiones creativas, de espacio y de tiempo, conforme Ra descubría y se descubría como artífice en regeneraciónmovimiento.

Oh dioses que están en la Duat [en la] primera caverna del Occidente, guardianes de los distritos de Igeret, jgrt, ${ }^{74}$ enéada del Regente del Occidente, yo soy Ra que está en el cielo, yo entro en las tinieblas del crepúsculo, yo abro la puerta del cielo en el Occidente. Miren, entro en la tierra del Occidente. Recíbanme, sus brazos extendidos hacia mí. Miren, yo conozco sus lugares en la Duat. Miren, yo conozco sus nombres, sus cavernas, sus secretos; yo sé de qué viven, cuando El de la Duat (Osiris) les ordena vivir. ${ }^{75}$

Finalmente, estos niveles de funcionalidad y relación que postulamos para el espacio en la base de la in-habitación, lejos de excluirse, se integran y coexisten de modo de conferirle a su dinámica la complejidad y originalidad que a lo largo del trabajo reclamamos. La interacción conjugada de los desplazamientos de Ra, sumados a su omnipresencia por cuanto eran sus "estados" los que progresivamente se descubrían y reproducían los de Osiris, inmersos ambos en una extensión inclusiva, sostiene la constitución integral del espacio entre los in-habitantes.

\section{Conclusiones}

La capacidad del sol no sólo de asumirse como Osiris para renacer reconvertido cada mañana a pesar de los embates del caos, sino también de generar un proceso de transferencia (luz, calor, vivificación y aniquilación) en todo el ámbito de la Duat y de este modo trascender incluso el mundo de los dioses, ${ }^{76}$ le otorga caracteres particulares.

${ }^{74}$ Región del silencio o silenciosa; la necrópolis. También Reino de los muertos, Totenreiches (Wiebach-Koepke, "Standorte-Bewegungstypen... ”, op. cit., p. 359).

${ }^{75}$ Libro de las Cavernas, $1,1$.

${ }^{76}$ Janák Jiri, "De Trinitate. An Outline of the Problem”, Göttinger Miszellen, núm. 178, 2000, p. 65. 
Ra y Osiris poseen, en su inmanencia, la capacidad de trascender sus capacidades respectivas; en el caso de $\mathrm{Ra}$, al aprehender la restauración desde la inmovilidad putrefacta por la posibilidad de disgregación o disociación ontoteológica, y en el caso de Osiris, al incorporar los fundamentos, luz y calor, para su propia restitución y, por carácter extensivo, para la de los que habitaban en sus dominios.

Dada la asimetría que rige el vínculo entre los dioses, es necesario remarcar que en lo que respecta a las 12 horas de la noche, constriñen a Osiris a un rol receptivo y expectante. El dominio de la temporalidad (objetivación-reconversiónvisitas provisionales) que Ra conlleva en su paso, debe entenderse como una cesión-compartir transitorio para la quietud osiriana.

La espacialidad, por su parte, entendida como la coexistencia de los in-habitantes en un área de transferencia, supone una relación más simétrica que la que surge de la temporalidad, por cuanto es un espacio compartido - por su creador y su regente- bajo una realidad de decaimiento simultáneo.

La transitividad de la relación, por lo tanto, determina que lo que ella conllevaba (espacialidad, temporalidad, movimiento, estatismo, etcétera) coactuará y se entrecruzará hasta casi difuminarse en el recorrido y su interacción. La preservación de la integridad osiriana es consecuencia de la mediación de $\mathrm{Ra}$ en el espacio del busirita, mientras que el apoyo cíclicoregenerativo estaba sustentado en la coincidencia en el espacio ontológico.

Para Ra, superar la muerte se vinculaba con una condición o estado provisorio, transicional, pero extremadamente peligroso para el orden cósmico; en este interregno se asume como Osiris y recorre sus dominios de quietud y descomposición. Su autogeneración se sustentaba en la inmanencia de su poder demiúrgico junto con la incorporación del poder generativo, contenido en la Duat y activado por su presencia (de Ra).

Osiris, por el contrario, en tanto representación de la suspensión cósmica, es decir, quietud y vigilia por la reactivación, y punto de convergencia de la fuerza generatriz en estado de desintegración en el contexto de la Duat, deviene cesionario de esta fuerza, pero sólo por la presencia revitalizadora solar. De 
este modo, Osiris transfería su propiedad generativa desde la inmovilidad y obtenía así la garantía de la detención de la putrefacción, pues frenaba e incluso revertía dicha situación. Su dominio de las limitaciones de la muerte se cimentaba entonces en la doble realidad de su potencia contenida y en su posterior activación por Ra.

Los Libros del Más Allá del Reino Nuevo estatuyen una variación en la concepción de la temporalidad en lo que se refiere a la ascendencia del caos sobre lo prefijado. Es decir, el diario proceso solar, ${ }^{77}$ al hacer incesantemente efectiva la amenaza del caos como realidad visible, exponía abiertamente la situación proveniente de la "anulación de las garantías" que la ausencia de $\mathrm{Ra}$ desencadenaba. En este sentido, el ciclo caos-orden se repetía periódicamente, en fases inevitables y no sometidas a acción humana alguna. La idea del antitiempo debe retenerse, dado que grafica cómo Ra y los dioses que remolcan su barca entran por la cola de la serpiente, Vida de los Dioses, como mayores y salen como jóvenes cada día, consecuencia de que en el Más Allá el tiempo puede ser reversible. ${ }^{78}$

Creo entonces que, en este contexto particular, conjunción y dominio de tiempos y espacios, cesión de "temporalidades", interacción para la regeneración, secuencialidad y simultaneidad, son los elementos que sustentan la relación entre Ra y Osiris.

Dirección institucional del autor:

Instituto de Historia Antigua Oriental "Dr. Abraham Rosenvasser"

25 de Mayo 217, $3^{\text {er }}$ piso

C1002ABD, Ciudad Autónoma de Buenos Aires

77 En el ciclo solar, el proceso suponía un límite inicial, la muerte, y uno final, la resurrección o reconversión, que si bien no dejaban de reproducirse, se manifestaban como realidad inmutable a partir de la muerte original. La recurrencia que implicaba el ciclo solar amenazado recreaba constantemente aquel proceso, pero como presencia dinámica activa.

${ }^{78}$ Libro del Amduat, 12,2. Kákosy, "Zeit”, op. cit., col. 1363. 


\section{Bibliografía}

Allen, James, "The Cosmology of the Pyramids Texts", en W. K. Simpson (ed.), Religion and Philosophy in Ancient Egypt, New Haven, Yale Egyptological Seminar, 1989, pp. 1-28.

AltenMÜller, Hartwig, Jenseitsbücher, Jenseitsführer, Leiden-Colonia, E. J. Brill, 1970, pp. 69-81.

AltenMÜller, Hartwig, Jenseitsvorstellungen (Ägypten), Beitrag im Internetlexikon, 2006. [bibelwissenschaft.de/stichwort/22307/, consultado en agosto de 2010.]

Assmann, Jan, Egyptian Solar Religion in New Kingdom. Re, Amun and the Crisis of Polytheism, Nueva York, Kegan Paul, 1995.

Assmann, Jan, "Sonnengottes”, Lexikon der Ägyptologie, Wiesbaden, Harrassowitz, 1984, vol. v.

Assmann, Jan, Zeit und Ewigkeit im Alten Ägypten. Ein Beitrag zur

Geschichte der Ewigkeit, Heidelberg, C. Winter, 1975.

BARTA, Winfried, Die Bedeutung der Jenseitsbücher für den vestorbenen König, Múnich, Deutscher Kunstverlag, 1985.

BARTA, Winfried, Die Bedeutung der Pyramidentexte für den vestorbenen König, Múnich, Deutscher Kunstverlag, 1981.

BARTA, Winfried, Komparative Untersuchungen zu vier Unterweltsbüchern, Frankfort del Meno-Berna-Nueva York-París, Peter Lang, 1994.

BINDER, Susanne, "The Hereafter: Ancient Egyptian Beliefs with Special Reference to the Amduat", Bulletin of the Australian Center for Egyptology, núm. 6, 1995, pp. 7-30.

BochI, Patricia, "Images of Time in Ancient Egyptian Art", Journal of the American Research Center in Egypt, núm. 31, 1994, pp. 55-62.

Bonanno, Mariano, La Duat como espacio de una dialéctica de la regeneración. In-habitación y resignificación del espacio funerario en los Textos del Amduat, Oxford, Archaeopress, 2015.

BONNET, Hans, Reallexikon der ägyptischen Religionsgeschichte, Berlín, De Gruyter Verlag, 1952.

BRUGSCH, Heinrich, Religion und Mytologie der Alten Aegypter, Leipzig, J. C. Hinrichs, 1891.

BudgE, Wallis, Osiris and the Egyptian Resurrection. Illustrated after Drawings from Egyptians Papyri and Monuments, Londres-Nueva York, Warner and Putnam, 1911 [reed. 1973].

Budge, Wallis, The Egyptian Heaven and Hell. Vol. III, Londres, Kegan Paul, Trench, Trübner \& Co. Ltd., 1905.

Castoriadis, Cornelius, La institución imaginaria de la sociedad, Buenos Aires, Tusquets, 1983 [reed. 2007]. 
CHASSINAT, Émile, "Étude sur quelques textes funéraires de provenance thébaine", Bulletin de l'Institut français d'archéologie orientale, núm. 3, 1903, pp. 129-163.

De Buck, Adrian, The Egyptian Coffin Texts, 7 vols., Chicago, The University of Chicago, 1935-1961.

ERman, Adolf y Hermann Grapow, Wörterbuch der Ägyptischen Sprache, 5 vols., Leipzig-Berlín, Akademie Verlag, 1971.

Faulkner, Raymond, The Ancient Egyptians Pyramid Texts, Oxford, Oxford University Press, 1969.

FrankFort, Henri, El pensamiento prefilosófico, Madrid, Fondo de Cultura Económica, 1954.

GARDINER, Alan, Egyptian Grammar. Being an Introduction to the Study of Hieroglyphs, Oxford, Griffith Institute, 1957.

GöRG, Manfred, Ägyptischen Religion, Stuttgart, W. Kohlhammer $\mathrm{GmbH}, 2007$.

Hegenbarth-Reichardt, Ina, Von Zeiten und Räumen. Oder: Wie unendlich ist die altägyptische Ewigkeit?, Berlín, Walter De Gruyter \& Co., 2009, pp. 3-28.

HofFMANN, Friedhelm, "Seilflechter in der Unterwelt", Zeitschrift für Papyrologie und Epigraphik, núm. 100, 1994, pp. 339-346.

Hornung, Erik, "Dat", en Wolfgang Helck, Eberhard Otto y Wolfhart Westendorf, Lexikon der Ägyptologie I, Wiesbaden, Harrassowitz, 1974, cols. 994-995.

HoRnung, Erik, "Die Verborgene Raum der Unterwelt in der ägyptischen Literatur", en A. Loprieno (ed.), Mensch und Raum von der Antike bis zur Gegenwart, Múnich-Leipzig, K. G. Saur, 2006, pp. 23-34.

Hornung, Erik, El Uno y los Múltiples. Concepciones egipcias de la divinidad, Madrid, Trotta, 1999.

HoRnUNG, Erik, "Zur Struktur des ägyptischen Jenseitsglaubens", Zeitschrift für ägyptische Sprache und Altertumskunde, núm. 119, 1992, pp. 124-130.

JIRI, Janák, "De Trinitate. An Outline of the Problem", Göttinger Miszellen, núm. 178, 2000, pp. 65-74.

KÁkоsy, Lazlo, "Zeit", en Wolfgang Helck y Eberhard Otto, Lexikon der Ägyptologie и, Weisbaden, Harrassowitz, 1986, cols. 1361-1371.

KeEs, Hermann, Totenglauben und Jenseits vorstellungen der Alten Agypter, Leipzig, C. Hinrischs'sche Buchhandlung, 1926.

Krauss, Rolf, Astronomische Konzepte und Jenseitsvorstellungen in den Pyramidentexte, Wiesbaden, Harrassowitz Verlag, 1997.

Lanzone, Ridolfo, Dizionario di Mitologia Egiziana. Le domicile des 
Esprits, París, Papyrus du Musée de Turin publié en fac-simile p. 1, 1879 [reed. 1974].

LeITZ, Christian, "Die obere und die untere Dat", Zeitschrift für ägyptische Sprache und Altertumskunde, núm. 116, 1989, pp. 4157.

Piankoff, Alexandre, The Tomb of Ramesses VI, 2 vols., Nueva York, Pantheon Books, 1954.

Pierret, Paul, "The Dogma of the Resurrection among the Ancient Egyptians”, The Old Testament Student, vol. 4, núm. 6, 1885, pp. 267-275.

QUIRKE, Stephen, Ancient Egyptian Religion, Londres, The British Museum Press, 1992.

SCHWEIZER, Andreas, The Sungod's Journey through the Netherworld. Reading the Ancient Egyptian Amduat, Ithaca-Londres, Cornell University Press, 2010.

Sethe, Kurt, Die ältagypschen Pyramidentexte nach den Papierabdrücken und Photographien des Berliner Museums, Leipzig, J. C. Hinrichs'sche Buchhandlung, 1908.

VAN Dijk, Jacobus, "The Nocturnal Wanderings of King Neferkare”, en Catherine Berger, Gisèle Clerc y Nicolas Grimal (comps.), Hommages à Jean Leclant, El Cairo, Institut français d'archéologie orientale, 1994, vol. 4, pp. 387-393.

WestendoRF, Wolfgang, "Das Ende der Unterwelt in der Amarnazeit oder: Die Erde als Klugel”, Göttinger Miszellen, núm. 187, 2002, pp. 101-111.

Wiebach-Koepke, Silvia, Sonnenlauf und Kosmische Regeneration. Zur Systematik der Lebensprozesse in den Unterweltsbüchern, Wiesbaden, Harrassowitz Verlag, 2007.

Wiebach-Koepke, Silvia, "Standorte-Bewegungstypen-Kreisläufe Semantische Betrachtungen zur Dynamik der Sonnenlaufprozesse in Amduat und Pfortenbuch", Studien zur Altägyptischen Kultur, núm. 24, 1997, pp. 337-366.

Wilson, John, "Egypt”, en Henri Frankfort, Before Philosophy. The Intellectual Adventure of Ancient Man. An Essay on Speculative Thought in the Ancient Near East, Middlesex, Penguin Books, 1946, pp. 31-121. 